\title{
Iron-deficiency anemia in infancy and poorer cognitive inhibitory control at age 10 years
}

\author{
CECILIA ALGARÍN ${ }^{1}$ | CHARLES A NELSON² | PATRICIO PEIRANO ${ }^{1}$ | ALISSA WESTERLUND² | \\ SUSSANNE REYES ${ }^{1}$ | BETSY LOZOFF ${ }^{3}$
}

1 Sleep and Functional Neurobiology Laboratory, Institute of Nutrition and Food Technology (INTA), University of Chile, Santiago, Chile; 2 Developmental Medicine Research, Harvard Medical School, Children's Hospital Boston, DMC Laboratories of Cognitive Neuroscience, Boston, MA; 3 Center for Human Growth and Development, University of Michigan, Ann Arbor, MI, USA

Correspondence to Cecilia Algarín, Sleep and Functional Neurobiology Laboratory, INTA, University of Chile, Av. El Líbano 5524, Macul, 7830490, Santiago, Chile. E-mail: calgarin@inta.uchile.cl

This article is commented on by Alloway on pages 401-402 of this issue.

\section{PUBLICATION DATA}

Accepted for publication 7th November 2012 Published online 7th March 2013

\section{ABBREVIATIONS \\ ERP Event-related potentials \\ $\mathrm{Hb} \quad$ Hemoglobin \\ IDA Iron-deficiency anemia \\ SES Socio-economic status}

AIM The aim of this study was to assess the effects of iron-deficiency anemia (IDA) in infancy on executive functioning at age 10 years, specifically inhibitory control on the Go/No-Go task. We predicted that children who had IDA in infancy would show poorer inhibitory control. METHOD We assessed cognitive inhibitory control in 132 Chilean children (mean [SD] age $10 y$ [ $1 \mathrm{mo}$ ]): 69 children had IDA in infancy ( 45 males, 24 females) and 63 comparison children who did not have IDA (26 males, 37 females). Participants performed the Go/No-Go task with event-related potentials. Group differences in behavioral (accuracy, reaction time) and electrophysiological outcomes (N2 and P300 components) were analyzed using repeatedmeasures analyses of variance. N2 and P300 are interpreted to reflect attention and resource allocation respectively.

RESULTS Relative to comparison participants, children who had IDA in infancy showed slower reaction time (mean [SE], 528.7ms [14.2] vs $485.0 \mathrm{~ms}$ [15.0], 95\% confidence interval [Cl] for difference between groups 0.9-86.5); lower accuracy $(95.4 \%$ [0.5] vs $96.9 \%$ [0.6], 95\% $\mathrm{Cl}-3.0$ to -0.1 ); longer latency to $\mathrm{N} 2$ peak (378.9ms [4.9] vs $356.9 \mathrm{~ms}$ [5.0], $95 \% \mathrm{Cl} 7.5-36.6$ ); and smaller $\mathrm{P} 300$ amplitude $(4.5 \mu \mathrm{V}[0.8]$ vs $7.6 \mu \mathrm{V}[0.9], 95 \% \mathrm{Cl}-5.5$ to -0.5$)$.

INTERPRETATION IDA in infancy was associated with slower reaction times and poorer inhibitory control 8 to 9 years after iron therapy. These findings are consistent with the long-lasting effects of early IDA on myelination and/or prefrontal-striatal circuits where dopamine is the major neurotransmitter.
The ability to inhibit inappropriate responses is crucial for optimal cognitive and social-emotional functioning ${ }^{1,2}$ Several neurotransmitters and brain regions are involved, but dopamine and prefrontal-striatal circuits are arguably the most important. ${ }^{3,4}$ Since iron-deficiency anemia (IDA) during early development adversely affects the cortex, striatum, and dopaminergic functioning, we undertook the present study to determine if there are long-term effects on inhibitory control and response inhibition. ${ }^{5}$

Inhibitory control is one of the earliest executive functions to begin developing. ${ }^{1,6,7}$ Its development has been studied electrophysiologically using event-related potentials (ERPs) in tasks that require active inhibition when there is a previously learned or prepotent response. ${ }^{8}$ Many such studies have used the $\mathrm{Go} / \mathrm{No}-\mathrm{Go}$ task to assess inhibitory control. ${ }^{9,10}$ The main relevant ERP components are the N2 and P300. The N2, an early negative deflection, has been interpreted to reflect attention. The P300, a later positive wave, is thought to reflect resource allocation. Attention and resource allocation are critical abilities with respect to cognitive development and long-term neurofunctional outcomes. The P300 is typically greater in the inhibitory than in the prepotent response components of tasks such as the Go/No-Go task, particularly in adult studies. ${ }^{11,12}$ Behavioral responses such as accuracy and reaction time have also been studied as measures of development. ${ }^{13} \mathrm{We}$ assessed cognitive inhibitory control using the Go/No-Go task in a follow-up study of 10-year-old children who did or did not have IDA as infants. In light of the protracted development of higher-order cognitive functions, the important role of dopamine in inhibitory control, and the short-term and long-term brain and behavioral effects of early IDA, we hypothesized that children who had IDA in infancy would show poorer inhibitory control than comparison participants. We also predicted longer reaction time owing to the long-lasting effects of early IDA on myelination. ${ }^{14}$ 


\section{METHOD}

\section{Participants}

Children in this follow-up study had participated in previous research on the behavioral, developmental, and neurofunctional effects of IDA in infancy. Detailed descriptions of the population and findings during infancy have been published elsewhere. ${ }^{14}$ In brief, study participants were healthy, term-born infants (birth weight $>3.0$ $\mathrm{kg}$, no perinatal complications, and no acute or chronic illnesses) identified as having IDA or not at 6, 12, or 18 months. Anemia was defined as venous hemoglobin $(\mathrm{Hb})$ of $100 \mathrm{~g} / \mathrm{L}$ or less at 6 months and less than $110 \mathrm{~g} / \mathrm{L}$ at 12 months and 18 months. Iron deficiency was defined as two of three iron measures in the iron-deficient range (mean cell volume $<70 \mathrm{fL}$, erythrocyte protoporphyrin $\geq 100 \mu \mathrm{g} / \mathrm{dL}$ red blood cells $[1.77 \mu \mathrm{mol} / \mathrm{L}]$, serum ferritin $<12 \mu \mathrm{g} / \mathrm{L}$ ) and/or an increase in $\mathrm{Hb} \geq 10 \mathrm{~g} / \mathrm{L}$ after 6 months of iron therapy. For each infant with IDA, the next infant of the same age who was clearly nonanemic (venous $\mathrm{Hb} \geq 115 \mathrm{~g} / \mathrm{L}$ ) was invited to join the study as part of the comparison group. The participants were given oral iron $(15 \mathrm{mg} / \mathrm{d}$ or $30 \mathrm{mg} / \mathrm{d}$, depending on age) for a minimum of 6 months and had normal $\mathrm{Hb}$ concentrations at the end of the study. Infants from the comparison group were given iron to prevent iron deficiency with advancing age in this setting where iron deficiency was widespread.

Between 2002 and 2006, we conducted neurocognitive testing with ERPs and collected blood to determine iron status of the children at 10 years. Of the available 10-yearold children who had been part of the earlier study $(6,12$, and $18 \mathrm{mo}$ IDA, and comparison groups), $72 \%$ agreed to participate, $7 \%$ declined further participation, and $21 \%$ could not be located or had moved outside the region. The protocol was approved by the institutional review boards of the University of Michigan, Ann Arbor, and the Institute of Nutrition and Food Technology (INTA), University of Chile, Santiago. Parents provided signed informed consent; children gave their assent.

\section{Iron status at age $\mathbf{1 0}$ years}

IDA was, again, defined as low $\mathrm{Hb}$ and two or more abnormal iron measures, using cut-offs for age $(\mathrm{Hb} \leq 11.8 \mathrm{~g} / \mathrm{dl}$, mean corpuscular volume $\leq 76 \mathrm{fL}$, transferrin saturation $\leq 14 \%$, free erythrocyte protoporphyrin $\geq 70 \mu \mathrm{g}$ per $\mathrm{dl}$ red blood cells $[1.24 \mu \mathrm{mol} / \mathrm{l}]$, and serum ferritin $[\leq 12 \mu \mathrm{g} / \mathrm{l}])$. Only three children had IDA at age 10 years; they were excluded from further analyses.

\section{Inhibitory task (Go/No-Go)}

Children were seated in front of a computer and were asked to press a button in response to the presentation of all letters (target stimuli) except for the letter ' $\mathrm{X}$ ' (nontarget stimuli), while trying to avoid mistakes. Each trial consisted of a single white upper-case letter presented in the center of a black computer screen. There were two blocks of trials: block 1 consisted of 40 trials containing

\section{What this paper adds}

- Ten-year-old children who had IDA in infancy had poorer behavioral performance in inhibitory control.

- Affected children showed electrophysiological evidence of poorer responses in inhibition and control.

- Results provide support for the hypothesis of long-term neurofunctional alterations with IDA in infancy.

$100 \%$ target stimuli (Go trials). These trials primed participants to respond to the target stimuli. Block 2 comprised 80 trials containing $50 \%$ target stimuli (Go trials) and $50 \%$ non-target stimuli (No-Go trials), corresponding to the response inhibition condition. ${ }^{12}$

ERPs were recorded from scalp electrodes (Electro-Cap International, Eaton, $\mathrm{OH}, \mathrm{USA}$ ) referenced to $\mathrm{Cz}$ (central scalp electrode) during acquisition. Data were also recorded at the left and right mastoids. To detect eyeblinks, bipolar vertical electro-oculography was carried out using electrodes placed vertically above and below the right eye. Electroencephalography (EEG) and electro-oculography were conducted using a Neurodata Acquisition System (Grass Instruments, West Warwick, RI, USA) and amplified with Model 15 amplifiers with a gain of 50000 for the scalp channels and 5000 for the electro-oculographic channels. The amplifier filter settings were 0.1 to $30.0 \mathrm{~Hz}$ with a $50 \mathrm{~Hz}$ notch filter. All channels were digitized at $200 \mathrm{~Hz}$ onto a hard drive with a 12-bit A/D converter (National Instruments, Austin, TX, USA). ERP data were edited offline with ERP32 analysis software (New Boundary Technologies, Minneapolis, MN, USA). Each trial lasted $1600 \mathrm{~ms}$ and consisted of $100 \mathrm{~ms}$ of pre-stimulus presentation, $500 \mathrm{~ms}$ of stimulus presentation, and $1000 \mathrm{~ms}$ of stimulus recording. The intertrial interval was 500 to $700 \mathrm{~ms}$. Data for a participant were included for analysis if there were at least 10 artifact-free trials for each of the three stimulus types: block 1 Go trials, block 2 Go trials, and block 2 No-Go trials.

For the ERP analysis, window time was selected to establish where to determine the components of interest, which were identified relative to the number of major positive and negative peaks following stimulus onset. All time window values were relative to stimulus onset, and the peak amplitudes were calculated relative to the baseline amplitude. Statistical analyses were conducted with SPSS software version 15.0.1 (SPSS Inc., Chicago, IL, USA). Behavioral measures were reaction time and accuracy. Electrophysiological measures were peak amplitude and latency for N2 and amplitude for P300. Covariates that indicated group differences (other than infancy hematology, which defined the groups) were considered in subsequent analyses as potential confounders (see Table I). Since several covariates were intercorrelated (i.e. socio-economic status [SES; a social class index measured by the Graffar scale], parental education, maternal depression, and presence of father), we included SES as the family background covariate. All models included SES, sex, and 10year iron status. When omnibus analyses of variance 


\begin{tabular}{|c|c|c|c|}
\hline & \multicolumn{2}{|l|}{ Group $(n)^{\mathrm{a}}$} & \multirow[b]{2}{*}{ Mean difference $(95 \% \mathrm{Cl})$} \\
\hline & Comparison $(n=63)$ & Former IDA ( $n=69)$ & \\
\hline \multicolumn{4}{|l|}{ Child } \\
\hline Age at test & $10 \mathrm{y}(1 \mathrm{mo})$ & $10 \mathrm{y}(1 \mathrm{mo})$ & $0.1 \mathrm{mo}(-0.3$ to $0.6 \mathrm{mo})$ \\
\hline Sex Male/Female $(n)$ & $41 / 22$ & $65 / 4$ & $-0.2(-0.4 \text { to }-0.1)^{\mathrm{b}}$ \\
\hline Birthweight (g) & $3573.2(402.7)$ & $3498.7(370.2)$ & $74.5(-58.6$ to 207.6$)$ \\
\hline Gestational age (wks) & $39.6(1.2)$ & $39.3(1.0)$ & $0.3(-0.0 \text { to } 0.7)^{\mathrm{c}}$ \\
\hline Height-for-age $z$-score at $10 y$ & $0.10(0.79)$ & $0.09(0.97)$ & $0.02(-0.29$ to 0.33$)$ \\
\hline Weight-for-age $z$-score at $10 y$ & $0.59(0.96)$ & $0.66(1.01)$ & $-0.07(-0.41$ to 0.28$)$ \\
\hline Body mass index $\left(\mathrm{kg} / \mathrm{m}^{2}\right)$ at $10 \mathrm{y}$ & $19.6(3.2)$ & $19.8(3.5)$ & $-0.2(-1.4$ to 1.0$)$ \\
\hline Head circumference $(\mathrm{cm})$ at $10 \mathrm{y}$ & $54.1(1.4)$ & $54.4(1.6)$ & $-0.2(-0.8$ to 0.3$)$ \\
\hline IQ, Wechsler Intelligence Scale for Children & $90.2(16.1)$ & $87.8(17.9)$ & $2.4(-3.6$ to 8.3$)$ \\
\hline \multicolumn{4}{|l|}{ Iron status in infancy } \\
\hline Hemoglobin (g/l) & $124.7(7.1)$ & $102.6(7.4)$ & $22.1(19.6 \text { to } 24.6)^{b}$ \\
\hline Mean corpuscular volume (fl) & $75.5(3.4)$ & $66.6(4.8)$ & $8.9(7.4 \text { to } 10.3)^{b}$ \\
\hline Free erythrocyte protoporphyrin ( $\mu \mathrm{g} / \mathrm{dl})$ & $86.8(22.4)$ & $170.7(74.6)$ & $-83.8(-103.2 \text { to }-64.5)^{\mathrm{b}}$ \\
\hline Ferritin $(\mu \mathrm{g} / \mathrm{l})$ & $15.4(11.3)$ & $6.2(6.1)$ & $9.2(6.0 \text { to } 12.2)^{\mathrm{b}}$ \\
\hline \multicolumn{4}{|l|}{ Iron status at $10 y$} \\
\hline Hemoglobin $(\mathrm{g} / \mathrm{l})$ & $136.9(8.8)$ & $131.6(8.9)$ & $5.3(1.9 \text { to } 8.7)^{\mathrm{b}}$ \\
\hline Mean corpuscular volume (fl) & $82.6(3.6)$ & $80.2(3.8)$ & $2.4(1.0 \text { to } 3.8)^{\mathrm{b}}$ \\
\hline Transferrin saturation (\%) & $28.0(10.7)$ & $24.3(11.3)$ & $3.7(-0.8$ to 8.2$)$ \\
\hline Free erythrocyte protoporphyrin $(\mu \mathrm{g} / \mathrm{dl})$ & $65.2(15.4)$ & $71.1(14.0)$ & $-5.9(-11.6 \text { to }-0.3)^{\mathrm{d}}$ \\
\hline Ferritin $(\mu \mathrm{g} / \mathrm{l})$ & $29.0(12.0)$ & $27.4(13.0)$ & $1.6(-4.0$ to 7.2$)$ \\
\hline \multicolumn{4}{|l|}{ Family } \\
\hline Maternal $1 Q^{\mathrm{e}}$ & $83.9(11.7)$ & $83.4(9.6)$ & $0.4(-3.4$ to 4.3$)$ \\
\hline Maternal education, y & $9.8(3.0)$ & $9.0(3.0)$ & $0.9(-0.2$ to 1.9$)$ \\
\hline Paternal education, y & $10.4(2.7)$ & $9.3(3.0)$ & $1.1(0.1 \text { to } 2.1)^{\mathrm{d}}$ \\
\hline Father present, \% $(n)$ & $87(53)$ & $68(46)$ & $0.19(0.05 \text { to } 0.34)^{d}$ \\
\hline Social class index ${ }^{f}$ & $32.3(7.2)$ & $35.0(6.8)$ & $-2.6(-5.1 \text { to }-0.2)^{\mathrm{d}}$ \\
\hline Life stress $^{g}$ & $4.6(2.5)$ & $5.2(2.6)$ & $-0.6(-1.4$ to 0.3$)$ \\
\hline Home environment ${ }^{\mathrm{h}}$ & $37.8(7.5)$ & $35.8(7.6)$ & $2.0(-0.7$ to 4.6$)$ \\
\hline Maternal depression ${ }^{i}$ & $15.0(12.0)$ & $20.8(15.0)$ & $-5.8(-10.6 \text { to }-1.0)^{\mathrm{d}}$ \\
\hline
\end{tabular}

${ }^{a}$ Numbers vary slightly owing to occasional missing data for some measures. ${ }^{b} p<0.01 .{ }^{c} p<0.10 .{ }^{d} p<0.05$. ${ }^{e}$ Maternal 10 was measured with an abbreviated version of the Wechsler Adult Intelligence Scale-Revised. ${ }^{f}$ Measured by the Graffar scale, designed to differentiate families at the lower end of the socio-economic spectrum. ${ }^{9}$ Measured by a scale modified from Holmes and Rahe. ${ }^{\mathrm{h}}$ Measured by the Home Observation for Measurement of the Environment-Revised. ${ }^{26}{ }^{\mathrm{i}}$ Measured by Center for Epidemiologic Studies Depression Scale. ${ }^{27}$ Values given are means (SD) for continuous variables and percentages $(n)$ for categorical variables.

(ANOVAs) revealed significant main effects or interactions, post-hoc paired $t$-tests were conducted using Bonferroni correction for multiple comparisons. All significance tests were two-tailed; a $p$-value $\leq 0.05$ was considered statistically significant. The within-participants factor was condition (block 1 Go, block 2 Go, and block 2 No-Go), and between-participants factor was group (comparison, former IDA).

\section{RESULTS}

Of 219 children, 132 had satisfactory ERP data for analysis (69 former IDA [65 males, 4 females] and 63 comparison children [41 males, 22 females]). Controlling for sex and SES, there were no group differences in the proportion of children with or without usable ERP data. Background characteristics for the 69 participants with previous IDA and 63 comparison participants are shown in Table I.

\section{ERP outcomes}

Table II summarizes the mean peak amplitude and latency to peak of N2 and P300 components for each type of condition (block 1 Go, block 2 Go, block 2 No-Go).
Table II: Mean (SD) peak amplitude and latency to peak of N2 and P300 components for each condition

\begin{tabular}{lllc}
\hline Condition & Block 1 - Go & Block 2 - Go & Block 2 - No-Go \\
\hline N2 amplitude $(\mu \mathrm{V})$ & $-10.4(6.2)$ & $-12.6(6.8)^{\mathrm{a}}$ & $-8.6(6.9)$ \\
N2 latency $(\mathrm{ms})$ & $381.7(57.7)$ & $353.6(39.5)^{\mathrm{a}}$ & $370.6(51.3)^{\mathrm{a}}$ \\
P300 amplitude $(\mu \mathrm{V})$ & $3.6(7.3)$ & $5.6(7.3)$ & $9.1(7.5)^{\mathrm{a}}$ \\
\hline
\end{tabular}

${ }^{\mathrm{a}} p \leq 0.01$.

\section{P300 component}

\section{Mean amplitude}

The P300 showed the greatest amplitude at the midline parietal region. The amplitudes were significantly greater in the block 2 No-Go trials than in the block 2 Go and block 1 Go trials $\quad(p<0.001$ for both comparisons; Table II). No covariates were significant in the final model. There was a main effect of group: amplitude was smaller in children who had IDA in infancy than in comparison participants (mean [SE] $4.5 \mu \mathrm{V}[0.8]$ vs $7.6 \mu \mathrm{V}$ [0.9]; $95 \%$ CI for group difference -5.5 to -0.5 ). Block 2 No-Go trials showed the most marked difference $(10.5 \mu \mathrm{V}$ [1.0] vs $7.7 \mu \mathrm{V}$ [0.9], $95 \% \mathrm{CI}$ for group difference $0.2-5.5$; see Fig. 1). 

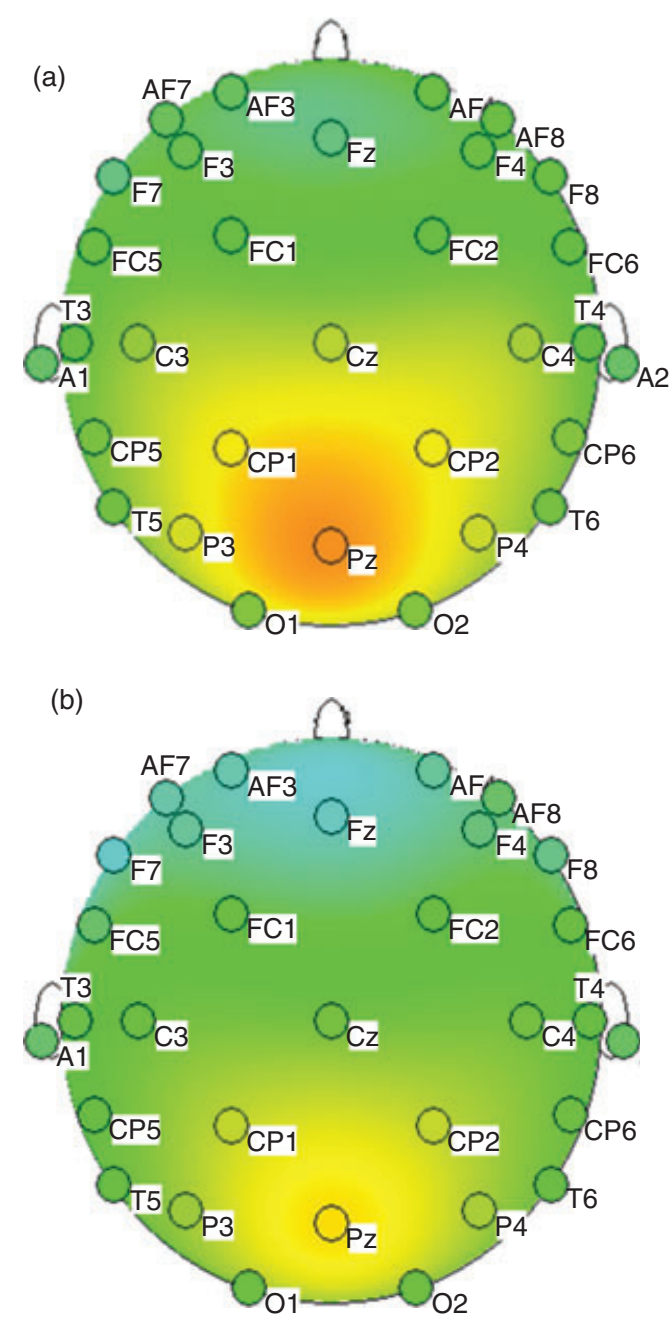

Figure 1: Topographic distribution of scalp potentials collapsed across block 1 Go, block 2 Go, and block 2 No-Go. (a) Comparison participants. (b) Children who had iron-deficiency anemia (IDA) in infancy.

\section{N2 component \\ Peak amplitude}

The N2 showed the greatest amplitude at the midline frontal region. Values were higher in block 2 Go trials than in block 1 Go and block 2 No-Go trials $(p<0.001$ for both comparisons; Table II). After controlling for significant background variables, there were no significant group differences.

\section{Latency to peak amplitude}

Overall, the latency to peak amplitude was shorter in block 2 Go trials than in block 1 Go and block 2 No-Go trials $(p<0.001$ for both comparisons; Table II). No covariate remained significant in the final model. The children who had IDA in infancy had slower responses than those in the comparison group (mean [SE] $378.9 \mathrm{~ms}$ [4.9] vs $356.9 \mathrm{~ms}$ [5.0]; $95 \%$ CI for group difference 7.5-36.6).

\section{Behavioral outcomes Accuracy}

As expected, participants performed better in block 1 Go trials than in block 2 Go or block 2 No-Go trials $(p<0.01$ for both comparisons; Table II). Controlling for sex, there was a main effect of group: children who had IDA in infancy were less accurate (mean [SE] 95.4\% [0.5] vs $96.9 \%$ [0.6]; $95 \%$ CI for group difference 3.0-0.1).

\section{Reaction time in conditions 1 and 2}

Overall, participants had faster reaction time for block 1 Go trials than for block 2 Go trials $(p=0.001$; Table II). No relevant background factors were significant in the final model; the children who had IDA in infancy were slower than children in the comparison group (mean [SE] $528.7 \mathrm{~ms}$ [14.2] vs $485.0 \mathrm{~ms}$ [15.0]; $95 \%$ CI for group difference 0.9-86.5). When block 1 Go and block 2 Go were analyzed separately, the difference in reaction time between children who had IDA in infancy and children in the comparison group was significant for block 2 Go trials (543.9ms [12.7] vs $499.5 \mathrm{~ms}[13.8] ; p=0.02 ; 95 \%$ CI for group difference -81.4 to -7.3 ; see Fig. 2). The difference for the block 1 Go trial did not reach statistical significance $(p=0.14)$.

The design of the infancy study also raised the question whether the age at which IDA was detected influenced the effects. We compared ERP outcomes in the 33 participants with IDA at 6 months with outcomes in those with IDA at 12 or 18 months ( $n=82$ and $n=17$ respectively). There were no statistically significant differences with regard to the age at which IDA was identified.

\section{DISCUSSION}

This study was undertaken to determine whether IDA in infancy affected cognitive inhibitory control and response inhibition in the long term. We found that, despite iron treatment in infancy, 4 years of formal schooling, and absence of IDA at the age of 10 years, children who had IDA in infancy performed worse on the Go/No-Go task

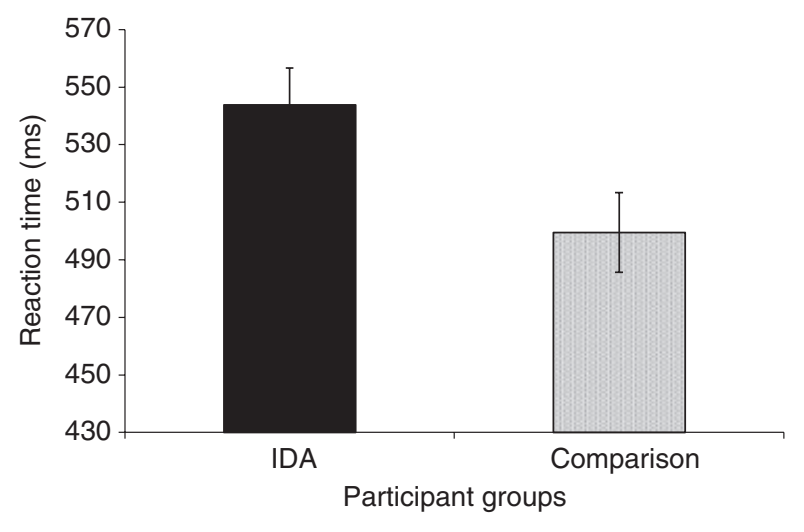

Figure 2: Reaction time (all conditions) in children who had irondeficiency anemia (IDA) in infancy and comparison participants $(p=0.02)$. 
than comparison participants. The study may help understand specific differences in brain system functioning in children who had IDA in infancy, which could underlie more global cognitive and behavioral dysfunctions. ${ }^{15}$ Such dysfunctions include alterations in motor activity and sleep patterns ${ }^{14,15}$ and poorer overall cognitive, motor, and social-emotional functioning ${ }^{16}$ observed years after iron treatment.

IDA in infancy could affect diverse brain functions through different pathways. Iron is involved in the biosynthesis of lipids, which are important substrates for cell membranes and the synthesis and metabolism of myelin. ${ }^{17}$ Iron is an essential component of cytochrome oxidase, which is thought to reflect neuronal metabolism, and is a cofactor in several enzymes involved in neurotransmitter metabolism. Dopamine is the neurotransmitter that has been studied the most in rodent models of dietary iron deficiency. There is evidence of alterations in dopamine transporter and D2 receptors that persist in spite of treatment. ${ }^{5,15}$ Other monoamine and non-monoamine neurotransmitters are also affected. ${ }^{18}$

\section{P300 component}

We found that the children who had IDA in infancy showed a smaller P300 amplitude, primarily in the inhibitory block 2 No-Go trials. There is general agreement that the P300 amplitude reflects the neural resources used for evaluating the response to an instructional task. For correct performance when a No-Go trial is presented, it is necessary to update the context and inhibit the prepotent response. ${ }^{9}$ An increase in P300 amplitude is expected and appears to reflect the increased activation of the neural circuits involved in these processes. ${ }^{13,19}$ The natural maturation of the P300 wave is a reduction in amplitude and latency from childhood to adolescence owing to fine-tuning of cognitive networks with pruning of synapses and increased myelination of the prefrontal cortex and its connections. ${ }^{12,19}$ However, smaller P300 amplitude has been described as a feature of psychiatric and developmental disorders. ${ }^{20,21}$ Pharmacological manipulations that decrease dopaminergic activity reversibly impair the P300 in both patients with Parkinson disease and healthy participants. ${ }^{21}$ Furthermore, the D2 dopamine receptor (DRD2) gene, specifically the A1+ genotype, has been associated with prolonged latency of the P300 in 12-year-old males and an interaction with stress for reduced P300 amplitude. ${ }^{19}$ Some researchers suggest that a smaller P300 could be used as a predictor of subsequent problems in children at risk of disorders of disinhibition. Prospective studies have found that a smaller P300 amplitude in children predicted later adolescent alcohol and substance abuse, ${ }^{22}$ conditions in which the dopamine system is strongly implicated. Our finding of smaller P300 amplitude in children who had IDA in infancy appears to be consistent with long-lasting dysfunction of the dopamine system and, consequently, the brain networks involving this neurotransmitter.

\section{N2 component}

In the present study, the N2 peak amplitude was greater in block 2 Go trials than No-Go trials, and there were no significant group differences. The N2 is generally considered an electrophysiological marker of attentional control. It is often enhanced under a condition in which there is a tendency to make a prepotent but incorrect response. In several adult studies, the No-Go-N2 has been found to be strongly enhanced compared with Go trials. Our finding of no enhancement of the No-Go-N2 might, therefore, appear puzzling. However, the No-Go-N2 is not enhanced in some pathological conditions such as depression or attention-deficit-hyperactivity disorder. ${ }^{23}$ Other factors may also explain why we did not observe enhanced No-Go-N2 or group differences. One possibility is the design of the task. Stimuli were presented on-screen for a relatively long time, allowing ample opportunity for responding with little or no speed pressure. A recent study showed that speed pressure modulates the response and contributes to the final amplitude of the N2. Without time pressure, there was no enhancement of N2, whether measured by amplitude or latency. ${ }^{24}$ Age is another important factor, as developmental studies have shown that children do not demonstrate a large difference in N2 amplitude until adolescence. ${ }^{12}$

In contrast to the absence of group differences in amplitude, we found that the comparison group had shorter N2 latency, in keeping with the behavioral response. This finding is consistent with a myelination dysfunction in children who had IDA in infancy, here reflected by longer N2 latency.

Accuracy rates were high in both groups, perhaps because of the relatively long response time allowed. That response window may have led to a ceiling effect for the number of correct responses for many in our sample. However, in spite of the relatively easy scenario, children who had IDA in infancy demonstrated worse performance. The lack of a sex effect is noteworthy in light of studies showing that development of gray and white matter in the prefrontal cortex peaks in females before adolescence. ${ }^{25}$

With respect to reaction time, both groups showed, for correct responses, shorter reaction time for block 1 Go trials than for block 2 Go trials. Nevertheless, the children who had IDA in infancy showed significantly longer reaction time than children in the comparison group. The longer N2 latency in the children who had IDA in infancy seems to be in keeping with these behavioral results. We previously showed that IDA in infancy is associated with longer auditory and visual evoked potential latencies at age 4 years, suggesting impaired myelin development. ${ }^{14}$ The reaction time and latencies results are consistent with longlasting effects of early IDA on myelination.

\section{Study limitations}

This study has several limitations. It cannot prove that IDA in infancy was the cause of altered ERP and behav- 
ioral responses, nor can it exclude the possibility of unidentified factors that may underlie both IDA and cognitive alterations. Although we consider some ways that IDA could have long-lasting effects, the mechanisms remain unclear. This study has more detailed information on the timing of IDA than most previous studies, but prenatal iron status was not determined. However, given the study design, no child had IDA in infancy for more than 6 months. The study also cannot determine whether the poorer cognitive inhibitory control in the children who had IDA in infancy will affect later cognitive functioning or scholastic achievement. Nonetheless, our findings are worrying and warrant continued follow-up. If the observed alterations have functional effects with advancing age, IDA in infancy may turn out to be important in understanding processes that underlie cognitive limitations in adulthood.

\section{CONCLUSION}

The results of this study extend our previous findings that early IDA is associated with altered neurofunctional development at preschool age. ${ }^{14}$ IDA in infancy appears to affect the efficiency of the neural systems underlying inhibitory control at the age of 10 years. Alterations of dopamine system functioning could be implicated in a smaller amplitude of the P300. Delayed myelination could contribute to longer reaction times and latencies. The combined effects could impair inhibitory control and response inhibition. We suggest that these subtle changes contribute to the limitations of cognitive development in children who experienced IDA in infancy. Since IDA in infancy continues to be common on a global basis, ${ }^{15}$ preventing it may improve the neurodevelopment of millions of the world's most vulnerable children.

\section{ACKN OWLEDGEMENTS}

This work was supported by grants from the National Institutes of Health, Bethesda, MD, USA (R01 HD33487) and the Chilean Agency for Funding in Science and Technology (CONICYT, Fondecyt 1070668). The content of this article is solely the responsibility of the authors and does not necessarily represent the official views of the National Institutes of Health.

\section{REFERENCES}

1. Davidson M, Amso D, Cruess Anderson L, Diamond A. Development of cognitive control and executive functions from 4 to 13 years: evidence from manipulations of memory, inhibition, and task switching. Neuropsychologia 2006; 44: 2037-78.

2. Hare TA, Tottenham N, Galvan A, Voss HU, Glover GH, Casey BJ. Biological substrates of emotional reactivity and regulation in adolescence during an emotional go-no-go task. Biol Psychiat 2008; 63: 927-34.

3. Casey BJ, Trainor R, Orendi J, et al. A developmental functional MRI study of prefrontal activation during performance of go-no-go task. 7 Cogn Neurosci 1997; 9: $835-47$.

4. Stevens MC, Kiehl KA, Pearlson GD, Calhoun VD. Functional neural networks underlying response inhibition in adolescents and adults. Behav Brain Res 2007; 181: 12-22.

5. Beard JL, Erikson KM, Jones BC. Neonatal iron deficiency results in irreversible changes in dopamine function in rats. 7 Nutr 2003; 133: 1174-9.

6. Christ SE, Steiner RD, Grange DK, Abrams RA, White DA. Inhibitory control in children with phenylketonuria. Dev Neuropsychol 2006; 30: 845-64.

7. Huizinga M, Dolan CV, van der Molen MW. Agerelated change in executive function: developmental trends and a latent variable analysis. Neuropsychologia 2006; 44: 2017-36.

8. Falkenstein M, Hoormann J, Hohnsbein J. Inhibitionrelated ERP components: variations with modality, age, and time-on-task. 7 Psychophysiol 2002; 16: 167-75.

9. Hirokazu B, Yamaguchi S, Kobayashi S. Electrophysiological correlates for response inhibition in a go/nogo task. Clin Neurophysiol 2001; 112: 2224-32.
10. Moyle JJ, Fox AM, Bynevelt M, Arthur M, Burnett JR. Event-related potentials elicited during a visual go-nogo task in adults with phenylketonuria. Clin Neurophysiol 2006; 117: 2154-60.

11. Nieuwenhuis S, Yeung N, Van den Wildenberg W, Ridderinkhof KR. Electrophysiological correlates of anterior cingulate function in a go/nogo task: effects of response conflict and trial type frequency. Cogn Aff Bebav Neurosci 2003; 3: 17-26.

12. Davis EP, Bruce J, Snyder K, Nelson CA. The X-trials: neural correlates of an inhibitory control task in children and adults. 7 Cogn Neurosci 2003; 15: 432-43.

13. Jonkman LM, Lansbergen M, Stauder JE. Developmental differences in behavioral and event related brain responses associated with response preparation and inhibition in a go/nogo task. Psychophysiology 2003; 40: 752 61.

14. Algarin C, Peirano P, Garrido M, Pizarro F, Lozoff B. Iron deficiency anemia in infancy: long-lasting effects on auditory and visual systems functioning. Pediatr Res 2003; 53: 217-23.

15. Lozoff B. Iron deficiency and child development. Food Nutr Bull 2007; 28: S560-71.

16. Lozoff B, Beard J, Connor J, Felt B, Georgieff M, Schallert T. Long-lasting neural and behavioral effects of iron deficiency in infancy. Nutr Rev 2006; 64: S34-43.

17. Connor JR, Menzies SL. Relationship of iron to oligodendrocytes and myelination. Glia 1996; 17: 83-93.

18. Unger EL, Paul T, Murray-Kolb LE, Felt B, Jones BC, Beard JL. Early iron deficiency alters sensorimotor development and brain monoamines in rats. 7 Nutr 2007; 137: 118-24.
19. Berman SM, Noble EP, Antolin T, Sheen C, Conner BT, Ritchie T. P300 development during adolescence: effects of DRD2 genotype. Clin Neurophysiol 2006; 117 : 649-59.

20. Stanzione P, Fattapposta F, Giunti P, et al. P300 variations in parkinsonian patients before and during dopaminergic monotherapy: a suggested dopamine component in P300. Electroenceph Clin Neurophysiol 1991; 80: $446-53$.

21. Ruchsow M, Groen G, Kiefer M, Hermle L, Spitzer M, Falkenstein M. Impulsiveness and ERP components in a go-nogo task. 7 Neural Trans 2008; 115: 909-15.

22. Antolin T, Berman SM, Conner BT, et al. D2 dopamine receptor (DRD2) gene, P300, and personality in children of alcoholics. Psychiatr Res 2009; 166: 91-101.

23. Fisher T, Aharon-Peretz J, Pratt H. Dis-regulation of response inhibition in adult attention deficit hyperactivity disorder (ADHD): an ERP study. Clin Neurophysiol 2011; 122: 2390-9.

24. Dong G, Yang L, Hu Y, Jiang Y. Is N2 associated with successful suppression of behavior responses in impulse control processes? NeuroReport 2009; 20: 537-42.

25. Groeschel S, Vollmer B, King MD, Connelly A. Developmental changes in cerebral grey and white matter volume from infancy to adulthood. Int 7 Dev Neurosci 2010; 28: 481-9.

26. Caldwell BM, Bradley RH. Home Observation for Measurement of the Environment (Revised edn). Little Rock: University of Arkansas, 1984.

27. Radloff L. The CES-D Scale: A self-report depression scale for research in the general population. Applied Psychological Measurement 1977; 1: 385-401. 